\title{
GENERAL TRUST AND INDIVIDUAL DIFFERENCES ON THE WASON SELECTION TASK WITH SHARING-RULE
}

\author{
Kai HIRAISHI'), Juko ANDO'), Yutaka ONO ${ }^{2)}$ \\ ${ }^{1)}$ The University of Tokyo, Japan, ${ }^{2)}$ Keio University, Japan \\ and \\ Toshikazu HASEGAWA ${ }^{1)}$ \\ ${ }^{1)}$ The University of Tokyo, Japan
}

\begin{abstract}
On the Wason selection task with the Sharing-rule, there are three major response patterns; 1) to select those cards that detect resource-provider's non-cooperation to in-group, 2) to select those cards that detect resource-provider's failure to exclude out-group parasitism, and 3) to select the cards that detect both types of rule violation. We examined the relationship between the individual differences on the Sharingrule Wason selection task and the participants' general trust level. Results showed lower general trusters tended to select the cards that detect resource-provider's failure to exclude out-group parasitism. The higher general trusters showed a tendency to select only the cards that detect non-cooperation by resource-provider. These results suggest that individual differences on social rule reasoning are related to respondents' perception, cognition, and attitude towards the social world.
\end{abstract}

Key words: Wason selection task, general trust, reasoning on social rule, individual differences

Individual differences on reasoning tasks have long been put outside of mainstream reasoning studies. Recently, several researchers have conducted studies on individual differences (Newstead, Handley, Harley, Wright, \& Farrelly, 2004; Stanovich \& West, $1998,2000,2003)$. In so doing, they mainly focus on the correlation between the reasoning task performances and general cognitive abilities (But see, de Jong, Mayer, \& van den Hout, 1997; Smeets, de Jong, \& Mayer, 2000).

This may be a fair approach when we think about performances on tasks that invoke abstract and analytical reasoning. For instance, Stanovich and West $(2000,2003)$ argued that people with higher cognitive abilities are more likely to produce normatively correct

Kai Hiraishi, Interfaculty Initiative in Information Studies, The University of Tokyo; Juko Ando, Faculty of Letters, Keio University; Yutaka Ono, School of Medicine, Keio University; Toshikazu Hasegawa, Graduate School of Arts and Sciences, The University of Tokyo.

This study was undertaken as a part of Keio Twin Project, and supported by a Keio University Special Grant-in-Aid Innovative Collaborative Research Project, and Human Frontier Science Program. It was also supported by a Grant-in-Aid for Scientific Research (A) No.13309014 (Project leader; Juko Ando) by Japanese Ministry of Education.

We thank Hiroshi Yama and Gary Brase for their fruitful comments.

Correspondence concerning this article should be addressed to Kai Hiraishi, College of Arts and Sciences, The University of Tokyo, Komaba 3-8-1, Meguro-ku, Tokyo 153-8902, Japan (e-mail: kai@darwin.c.utokyo.ac.jp). 
answers on several reasoning tasks that are well known for their power to "bias" human reasoning. It has been shown, however, that social rules require quite different reasoning processes than abstract rules. For instance, respondents answer correctly on the Wason selection task when given a social rule like "if a person is drinking beer, the person must be over 19," though the task is very difficult with abstract rules (Cox \& Griggs, 1982). Most researchers agree that the social nature of the rule, not the familiarity or the concreteness of it, produces such content effect. It is also argued that social rule reasoning is more automatic and demands less cognitive capacity than abstract and analytical reasoning (Stanovich \& West, 2000, 2003; But see, Newstead et al., 2004; Oaksford, Morris, Grainger, \& Williams, 1996).

Given the difference between the reasoning on abstract rules and that on social rules, we would expect that something other than general cognitive abilities to play an important role in producing individual differences on the latter, although we do not deny the effects of general cognitive abilities. Specifically, we hypothesized that respondents' attitude towards social environment would affect their reasoning on social rules. Here we report that performances on the Wason selection task with the Sharing-rule are related to respondents' views on the trustworthiness of people in general.

\section{Wason Selection Task With Sharing-Rule}

Wason selection task (Wason, 1968) is a reasoning task on which respondents are required to reason about a conditional rule if $p$ then $q$. In the abstract Wason selection task, four cards are presented with a letter on one side and a number on the other. Then a conditional rule is given, for example, "if one side of a card is $\mathrm{K}$, then the other side is 5." The four cards show only one side - K, D, 5, and 9 - and each card corresponds to $p$, not- $p, q$, and not- $q$, respectively. The task is to indicate those cards that need to be turned over in order to check whether the rule is true or false. The rate of logically correct answers on the abstract Wason selection task is, despite its apparent simplicity, very low. Although the correct answer is $p$ and not- $q$ selection, modal responses are often only $p$ selection or $p$ and $q$ selection (Newstead \& Evans, 1995).

On the other hand, usage of a deontic conditional drastically changes the answer: Many respondents come to choose $p$ and not- $q$ (logically correct answer), not- $p$ and $q$, or all four cards (Dominowski, 1995). For example, in Cox and Griggs (1982), respondents were given a rule "if a person is drinking beer, then the person must be over 19" and were told that the four cards represented four people at a bar. Then they were asked to choose the cards that indicate whether or not anyone has violated the rule. It was shown that many respondents chose the logically correct $p$ (drinking a beer) and not- $q$ (16 years of age) cards. This is called the content effect.

Several hypotheses have been proposed to explain the content effect (e.g., Cheng \& Holyoak, 1985; Cosmides \& Tooby, 1992; Manktelow \& Over, 1991; Sperber, Cara, \& Girotto, 1995), and there still remains intense controversy. Most researchers, however, agree that people are choosing those cards that detect violation of social rules. For instance, by selecting the "drinking a beer" card and the "16 years of age" card, respondents can detect a case where one who is under 19 years old is drinking beer. 
However, the definition of violation can be different for different social rules and for different situations. For instance, Manktelow and Over (1991) argued that the same rule, "if you tidy your room, you may go out to play" can be interpreted differently depending on whether one stands in the perspective of the mother or the child. The mother will think it to be a violation if the child goes outside without tidying his room. On the other hand, the child will think it to be a violation if the mother does not let him go out after he has cleaned up the room.

Hiraishi and Hasegawa (2001) found a case where respondents' understandings differ even for the same rule viewed from the same perspective. They devised a Wason selection task with a Sharing-rule, "if one is from the in-group, one gets the resource." The context was that a person is providing a resource to his in-group members. Respondents were asked to imagine that they were an in-group member of the provider, and check whether or not the provider is following the Sharing-rule.

There are two possible violations of the Sharing-rule. One is to provide the resource to out-group members, thus letting out-group parasitism happen. In order to detect this violation, one should check the not- $p$ (out-group) card and the $q$ (get the resource) card. The other violation is failing to provide the resource to in-group members, which means non-cooperation by the provider. In order to detect this violation, one should check the $p$ (in-group) card and the not- $q$ (not get the resource) card.

Hiraishi and Hasegawa (2001) found that there were three major response patterns to the problem. Some respondents chose those cards that detect provider's failure to exclude out-group parasitism (not- $p$ and $q$ ) while others chose those cards that detect provider's non-cooperation to in-group ( $p$ and not- $q$ ). There were also respondents who chose all the cards, thereby detecting both types of rule violations.

The results suggested that there are different views on the relationship between ingroup and out-group, and those different views produced the different response patterns on the Sharing-rule Wason selection task. That is, when there are cooperative relationships within one's in-group, some people think it to be important to exclude outgroup from the cooperative relationships of the in-group while others think it important to enforce other in-group members to cooperate. Of course there are also people who think that both are equally important.

\section{General Trust}

Yamagishi's (1998) theory on general trust poses an interesting insight to the individual differences on the Sharing-rule Wason selection task. He argued that trust is important in constructing social relationship with others under social uncertainty. For instance, when we rent a car, we do "not examine every word of the contract closely, nor ask for convincing explanations for each word or phrase not completely understood" (Yamagishi, 1998, Chapter 1). We just trust the rent-a-car company that they would not harm us, and sign the contract. If we cannot trust the company, it would cost much more time and effort.

Yamagishi (1998) argued that there are two qualitatively different types of "trust"; trust in the narrow sense and assurance of security. Trust in the narrow sense is the 
expectation that a person does not intend to act in an exploitative manner depending on information about his or her behavioral disposition (Yamagishi, 1998, Chapter 2).

On the other hand, assurance is the expectation of "someone's benign behavior that is rooted in the evaluation of his self-interest" (Yamagishi, 1998, Chapter 2). For instance, we can expect that a person will not exploit us if we know she is a good person. This is the trust in the narrow sense. At the same time, we can expect a benign behavior even from a bad person if we know that vicious behavior would harm his self interest. This is assurance of security. Hereafter, we will use "trust" with quotation marks to refer to the word in the broader sense, while trust without the quotations refers to the word in the narrow sense.

Yamagishi (1998) argued that keeping default expectations of others' trustworthiness high is critical for constructing new relationships with others outside of current relationships. For instance, within one's in-group, one can rely on assurance since each group member knows each other very well, and their interests are heavily interrelated. Once one gets outside of her in-group, however, one cannot rely on assurance, so she has to rely on the trust. Then, if one's default expectation of others' trustworthiness is low, she will not trust anyone, thus not be able to construct any new social relationship. However, if one has a high default expectation about others' trustworthiness, one will have more chance to construct new relationships. Yamagishi called the default expectations of others' trustworthiness as general trust, and referred to his theory as the emancipation theory of trust.

However, keeping one's general trust high can be risky as well as it is beneficial. Since people with high levels of general trust are more likely to trust strangers, they are more likely to be exploited by viciously intended people. To avoid it, higher general trusters should pay more attention to the information about others' traits that indicate their trustworthiness. In fact, with many social psychological experiments, Yamagishi and his colleagues demonstrated that high general trusters are more sensitive to the information potentially revealing others' trustworthiness (e.g., Kosugi \& Yamagishi, 1996), and are more accurate in predicting others' cooperative tendency in the Prisoner's dilemma game (e.g., Kikuchi, Watanabe, \& Yamagishi, 1997; for review of general trust studies, see Yamagishi, 1998).

On the other hand, keeping a lower general level of trust can avoid the danger of exploitation. At the same time, however, one cannot go outside his in-group and has to meet the entire social requirement within the in-group. Therefore it will be critical for him to maintain the harmonious relationships within the in-group, and to exclude out-group members from his in-group interests.

\section{Sharing-Rule Wason Selection Task and the General Trust}

The theory of general trust by Yamagishi (1998) argues that people with lower general trust tend to pay more attention to information that may harm group interests. On the other hand, people with higher general trust are more sensitive to the information about others' trustworthiness. We propose that these patterns of individual differences will be reflected in the response patterns on the Sharing-rule Wason selection task. 

1) "Most people are basically honest."
2) "I am trustful."
3) "Most people are basically good and kind."
4) "Most people are trustful of others."
5) "Most people are trustworthy."

Fig. 1. Items of the General trust scale (Yamagishi, 1998).

On the Sharing-rule Wason selection task, respondents may check either provider's failure to exclude out-group parasitism, provider's non-cooperation to in-group, or both. The first response could reflect the respondents' intension to exclude out-group from cooperative relationship within in-group.

The second could reflect the intension to check others' cooperativeness. Since the provider is from the in-group, she may cooperate based on calculation of her self-interest. Hence, those who rely on assurance of security would not have to check the provider's cooperativeness. On the other hand, those who do not rely on assurance of security, in other words those who with higher general trust level, would check the cooperativeness or trustworthiness of the provider. Therefore we proposed two hypotheses.

\section{Hypothesis 1}

People with lower general trust, who are more sensitive to harms imposed by outgroup members, will be more likely to select those cards that detect provider's failure to exclude out-group parasitism on the Sharing-rule Wason selection task; the not-p (outgroup) card and the $q$ (get the resource) card.

\section{Hypothesis 2}

People with higher general trust, who do not rely on assurance of security and are more sensitive to others' trustworthiness, will be more likely to select those cards that detect provider's non-cooperation on the Sharing-rule Wason selection task; the $p$ (ingroup) card and the not- $q$ (not get the resource) card.

\section{METHOD}

\section{Participants and Procedure:}

One hundred and sixty undergraduates from Keio University and 88 undergraduates from Tokyo Gakugei University participated in the Study (Total, 248 participants; 106 women and 137 men, mean age $=19.2$ years). The study was conducted as a part of psychology class requirement and no reward for participation was paid. Participants were given a booklet that contained the general trust scale, the Sharingrule Wason selection task, and three other scales that measured participants' subjective well being (Japanese version of SUBI; Tonan, Sonoda, \& Ono, 1995), anxiety and depression (Japanese version of HADS-D; Kitamura, 1993), and eating behaviour (Japanese version of EDI; Nagata, Kiriike, Matsunaga, Iketani, Yoshida, \& Yamagami, 1994). All participants were presented the general trust measurement first, followed by the HADS-D, then answered the Wason selection task. EDI and SUBI followed the Wason selection task. 
When you came to the stadium to cheer for the base ball team at your high school (X high school), a team member was providing fruit juice to the audience saying "if you are from $X$ high school, you get a glass of juice." You want to verify whether the team member is following his own statement. Below, you are presented with currently available information about few people. The information is either about what high school he/she belongs to or about whether he/she gets the juice from the team member. To which person, do you need to further check information that is currently unknown? Please indicate by circling either "Yes" or "No" (you may need to check all four persons, or you may not need to check anyone).

Mr. A: Could not get the juice from the member.

Do you need to check what high school he belongs to? (Yes or No)

Mr. B: Gets the juice from the member.

Do you need to check what high school he belongs to? (Yes or No)

Mr. C: Belongs to X high school.

Do you need to check whether he gets the juice from the member? (Yes or No)

Mr. D: Belongs to Y high school.

Do you need to check whether he gets the juice from the member? (Yes or No)

Fig. 2. Sharing-rule Wason selection task used as the material. Mr. A matches the "not get the resource" (not- $q$ ) card. Mr. B matches the "get the resource" $(q)$ card. Mr. C matches the "in-group" $(p)$ card. Mr. D matches the "out-group" (not- $p$ ) card. Since we do not distinguish Mr. and Ms. in Japanese, sex of each person was not specified in the original material.

Materials:

General trust scale. General trust scale provided by Yamagishi (1998) was used. The scale is a seven level Likert scale (completely agree to completely disagree) composed of five items (Fig. 1). Examples of the items are, "Most people are basically honest", "Most people are trustful of others." For each item, we gave seven points to the respondents who answered "completely agree" and one point to those who answered "completely disagree" (all the items were in the same direction). Then the sum of the five items was calculated for each respondent. Therefore the general trust scale ranged from seven to 35 points, higher points indicating higher general trust level of the respondent.

The Wason selection task. The scenario was that when subjects were watching a baseball game between their high school and a rival high school at a stadium, a team member from their high school came to provide glasses of juice to the audience. The member said that "if one is from my high school, one gets a glass of juice." Then respondents were asked to check whether or not the member follows the rule. In order to embed the Wason selection task naturally among other scales, instead of presenting cards, we presented sentences to describe an audience, and asked whether or not the unknown information about her should be checked (Fig. 2). For convenience, below we will refer to each sentence as card in this paper.

\section{RESULTS}

\section{General Trust}

The mean score for the general trust scale was 20.2 points $(S D=5.72)$. The Cronbach alpha was .83 indicating high reliability.

\section{Sharing-Rule Wason Selection Task}

The most frequent selection pattern was to choose all the four cases ( $p$, not- $p, q$, and 
Table 1. Frequencies and Percentages of Selection Patterns

\begin{tabular}{lcr}
\hline Pattern & Frequency & $\%$ \\
\hline No card & 40 & 16.1 \\
not- $p \& q$ & 22 & 8.9 \\
$p \&$ not- $q$ & 32 & 12.9 \\
All four & 65 & 26.2 \\
Others & 89 & 35.9 \\
\hline Total & 248 & 100.0 \\
\hline
\end{tabular}

not- $q$ selection, $26.2 \%$, Table 1). The percentage of just $p$ and not- $q$ selection and nothing else was $12.9 \%$ and that of just not-p and $q$ selection and nothing else was $8.9 \%$. They were third and forth most frequent response patterns. What was most different from the preceding study (Hiraishi \& Hasegawa, 2001) was an unusually high percentage of no card selection (16.1\%). This was the second most frequent response. This may be because we explicitly stated the possibility of no card selection in the material (see Fig. 2). Otherwise, the individual differences reported by Hiraishi and Hasegawa were observed in the current study as well.

\section{General Trust and Sharing-Rule Wason Selection Task}

We hypothesized that 1) lower general trusters are more likely to choose the not-p (out-group) card and the $q$ (get the resource) card, and 2) higher general trusters are more likely to choose the $p$ (in-group) card and the not- $q$ (not get the resource) card. In order to test the hypothesis, we used a median split of scores to classify participants into high trusters $(n=123)$ and low trusters $(n=125)$. The mean general trust scores were 24.9 for high trusters and 15.7 for low trusters. The difference between them was highly significant $(t(246)=20.68, p<.0001)$.

Card selections. First, we compared the individual card selections (Table 2). From hypothesis 1 , it was predicted that percentages of not- $p$ card selection and $q$ card selection would be higher among low trusters. This was supported for both not- $p$ card and $q$ card. The percentages of not- $p$ card selection were $58.4 \%$ for low trusters and $41.5 \%$ for high trusters, and the difference was significant $\left(\chi^{2}(1, N=248)=7.11, p<.01\right)$. Likewise, the percentages of $q$ card selection were significantly higher for low trusters than for high trusters $\left(64.0 \%\right.$ for low trusters vs. $46.3 \%$ for high trusters; $\left.\chi^{2}(1, N=248)=7.82, p<.01\right)$.

From hypothesis 2 , it was predicted that percentages of $p$ card selection and not- $q$ card selection would be higher among high trusters. This was not supported. The percentages of $p$ card selection were $61.0 \%$ for high trusters and $55.2 \%$ for low trusters. The percentages of not- $q$ selection were $61.8 \%$ for high trusters and $58.4 \%$ for low trusters. Although the differences were shown in the predicted direction, they were not significant.

Selection patterns. Next, we compared the selection patterns between high trusters 
Table 2. Percentages of Each Card Selection by General Trust Level

\begin{tabular}{cccccc}
\hline & \multicolumn{2}{c}{ Failure to exclude out-group } & & \multicolumn{2}{c}{ Non-cooperation to in-group } \\
\cline { 2 - 3 } \cline { 5 - 6 } General Trust & $\begin{array}{c}\text { not- } p \\
\text { Out-group }\end{array}$ & $\begin{array}{c}q \\
\text { Get resource }\end{array}$ & & $\begin{array}{c}p \\
\text { In-group }\end{array}$ & $\begin{array}{c}\text { not- } q \\
\text { Not get resource }\end{array}$ \\
\hline High & 41.5 & 46.3 & & 61.0 & 61.8 \\
Low & $58.4^{*}$ & $64.0^{*}$ & & 55.2 & 58.4 \\
\hline
\end{tabular}

Note: Logical (e.g., p, not-q) and semantic (e.g., "in-group" "not get resource") category of each card was presented. Each card was classified by type of violation (e.g., "non-cooperation to in-group") that can be detected by selecting the card.

$* p<.05$.

Table 3. Percentages of Selection Patterns and Relevant Cards Selections by General Trust Level

\begin{tabular}{|c|c|c|c|c|}
\hline \multirow[b]{3}{*}{ General Trust } & \multicolumn{2}{|c|}{ Selection Pattern } & \multicolumn{2}{|c|}{ Relevant Cards Selection } \\
\hline & not- $p \& q$ & $p \&$ not- $q$ & "not-p \& q" & "p \& not- $q "$ \\
\hline & $\begin{array}{c}\text { Failure to exclude } \\
\text { out-group }\end{array}$ & $\begin{array}{l}\text { Non-cooperation } \\
\text { to in-group }\end{array}$ & $\begin{array}{c}\text { Failure to exclude } \\
\text { out-group }\end{array}$ & $\begin{array}{l}\text { Non-cooperation } \\
\text { to in-group }\end{array}$ \\
\hline High & 5.7 & $17.9 *$ & 35.0 & 49.6 \\
\hline Low & $12.0^{+}$ & 8.0 & $50.4^{*}$ & 41.6 \\
\hline
\end{tabular}

Note: "Selection pattern" means selecting not- $p, q$ and nothing else, or $p$, not- $q$ and nothing else. "Relevant cards selection" means selecting not- $p$ and $q$ irrespective of other cards, or selecting $p$ and not- $q$ irrespective of others. The type of violation that can be detected by each selection pattern or relevant cards selection was presented. ${ }^{+} p<.1 .{ }^{*} p<.05$.

and low trusters (Table 3). From hypothesis 1, the percentages of just not- $p$ and $q$ selection and nothing else were predicted to be higher among low trusters. The difference between high trusters and low trusters was in the predicted direction $(12.0 \%$ for low trusters and $5.7 \%$ for high trusters $)$ and approached significance level $\left(\chi^{2}(1, N=248)=3.05\right.$, $p=.081)$.

Hypothesis 2 predicted that percentages of just $p$ and not- $q$ selection and nothing else would be higher among high trusters. This was supported. The percentages were $17.9 \%$ for high trusters and $8.0 \%$ for low trusters. The difference was significant $\left(\chi^{2}(1\right.$, $N=248)=5.39, p<.05$ ).

Relevant cards selections. Substantial number of participants selected one or two more cards in addition to $p$ and not- $q$ selection or not- $p$ and $q$ selection; like, $p$, not- $p$, and not- $q$ selection. Hypothesis 1 was that lower general trusters are more likely to check provider's failure to exclude out-group parasitism and select those cards that are "relevant" for the goal. This does not mean that we must exclude the possibility that low trusters check non-cooperation by the provider. Therefore, we compared the percentages 
of participants who selected the relevant not- $p$ card and the $q$ card disregarding their choices of other irrelevant cards (Table 3). Then hypothesis 1 predicted higher "not-p and $q$ " selection among low trusters. This was supported. The percentages of "not- $p$ and $q$ " selection were $35.0 \%$ for high trusters and $50.4 \%$ for low trusters $\left(\chi^{2}(1,248)=6.04\right.$, $p<0.05)$.

In the same way, we compared the percentages of " $p$ and not- $q$ " selections (Table 3). Hypothesis 2 predicted higher " $p$ and not- $q$ " selections among high trusters. This was not supported. The percentages were $49.6 \%$ for high trusters and $41.6 \%$ for low trusters. Though the difference was in the predicted direction, it was not significant $\left(\chi^{2}(1\right.$, $N=248)=1.60, n s)$.

\section{DISCUSSION}

We hypothesized that responses on the Wason selection task with the Sharing-rule would be affected by the respondents' level of general trust. Specifically we predicted 1) people with lower general trust is more likely to choose the not- $p$ card and the $q$ card, those cards that detect provider's failure to exclude out-group parasitism, and 2) people with higher general trust are more likely to choose the $p$ card and the not- $q$ card, those cards that detect provider's non-cooperation to in-group. The data were generally in the predicted direction. Still, there were some ambiguities about the results.

\section{Why the Difference Between Card Selections and Selection Patterns?}

One important problem with the current data is the "flip" of the results between individual card selections and selection patterns. When we look at individual card selections, it was hypothesis 1 that was supported more strongly. When it comes to the selection patterns (e.g., just $p$ and not- $q$ selection and nothing else), however, hypothesis 2 received stronger support. When we look at the relevant cards selections though, hypothesis 1 received stronger support once again.

These results may show that low trusters tended to choose one or two more cards in addition to the cards relevant to detecting resource-provider's failure to exclude out-group parasitism. This is understandable since checking the resource provider's trustworthiness may be beneficial to the cooperative relationship within the group, though this argument contradicts the hypothesis 2 . If this is the case, we would see that low trusters are more likely to choose not- $p$ card and $q$ card than high trusters, but their response patterns are not necessarily just not- $p$ and $q$ selection and nothing else. This is one reason why we could have stronger support for hypothesis 1 from the individual card selections and the relevant cards selection, but not from the selection patterns.

On the other hand, high trusters may not have been inclined to choose additional not$p$ and/or $q$ cards that are important to exclude out-group parasitism. This may be because high trusters, who were willing to construct relationships with out-group members as well as in-group members, were less interested in protecting the benefit of the in-group as a whole. So they were less inclined to exclude out-group members from the cooperative 
relationship. There is even a possibility that high trusters thought that that kind of group centrism was untenable. If this was the case, high trusters would have had a tendency to check only those cards that were relevant to detection of non-cooperation by the provider ( $p$ and not- $q$ ), and never selecting other cards. Since there were some low trusters choosing $p$ card and/or not- $q$ card, when we look at the individual card selections or relevant cards selections, the differences between high trusters and low trusters diminish. When we look at the selection pattern, however, we could see a clear difference between high trusters and low trusters. This is one reason why we had stronger support for hypothesis 2 from the selection patterns but not from individual card selections and relevant cards selection.

In support of the argument, we compared the number of "irrelevant" cards selected; those cards that we predicted less likely to be selected by each general trust class; not- $p$ and $q$ for high trusters and $p$ and not- $q$ for low trusters. The difference was significant (mean number of irrelevant cards; high trusters 0.88 vs. low trusters, 1.14; Wilcoxon test, $z=-2.32, p<.05)$. On the other hand, when we looked at the number of "relevant" cards selected, the mean numbers were almost the same for the high trusters and low trusters (mean number of relevant cards; high trusters 1.23 vs. low trusters, 1.23; Wilcoxon test, $z=0.00, n s)$. These data indicated that low trusters were more likely to select irrelecvant cards ( $p$ and/or not $-q$ ) in addition to relevant cards (not- $p$ and/or $q$ ).

In summary, the results supported hypothesis 1 while they did not lend strong support for hypothesis 2. However, at least we can say that the data showed the relationship between the general trust level and the response on the Sharing-rule Wason selection task. Since this study is rather a preliminary one, further research will be required to examine the relationships between social views and social reasoning in detail.

\section{Implications for Thinking and Reasoning Study}

The current study was not intended to test any specific theory about reasoning. We believe that most of the theories will find it easy to explain the current data. For instance, the evolutionary theory proposed by Cosmides, Tooby, and Fiddick (Cosmides \& Tooby, 1992; Fiddick, Cosmides, \& Tooby, 2000) will explain the individual differences as a result of individually differentiated activation criteria of Darwinian modules (Tooby \& Cosmides, 1990). The deontic reasoning theory by Manktelow and Over (1991) would argue that people have different preferences about social matters, and that difference affected the performance. Therefore, if we are interested only in testing reasoning theories, apparently this study may not have great contribution for the advance of the field.

Nonetheless, we believe that the current study will pose an important insight into the field of reasoning study. First, there is a possibility that current findings can be extended to test competing theories on reasoning. For instance, it is conceivable that general trust level, which is supposed to be related to views on social environment, affects the reasoning about rules that regulate social behavior but not about rules that regulate precautionary behavior in physical danger (e.g., if you ride a motorcycle, you must wear a helmet). If this is the case, it will lend stronger support for the theories that discriminate the two types of rules (e.g., Social contract theory; Cosmides \& Tooby, 1992; Fiddick, 
Cosmides, \& Tooby, 2000) than for the theories that take them to be the same (e.g., Pragmatic Reasoning Schema theory; Cheng \& Holyoak, 1985). This possibility suggests a potential usefulness of individual difference research in reasoning study.

Second, it has been argued that reasoning on social rules is more contextualized, automatic, and intuitive (Stanovich \& West, 2003). At the same time, social rules are kind of conditional rules that people face in everyday life, and how we interpret the social rules could have a large impact on our welfare (Cummins, 1996). Then, if our intuitive interpretation of such important social rules differ among people, as the current study showed, it could lead to disastrous consequences. We believe elucidating the mechanisms that produce such differences is an important task imposed on reasoning researchers.

\section{REFERENCES}

Cheng, P. W., \& Holyoak, K. J. 1985. Pragmatic Reasoning Schemas. Cognitive Psychology, 17, 391-416.

Cosmides, L., \& Tooby, J. 1992. Cognitive Adaptations for Social Exchange. In J. Barkow, L. Cosmides, \& J. Tooby (Eds.), The adapted mind (pp. 163-228). New York: Oxford University Press.

Cox, J. R., \& Griggs, R. A. 1982. The effect of experience on performance in Wason's selection task. Memory and Cognition, 10, 496-502.

Cummins, D. D. 1996. Evidence for the innateness of deontic reasoning. Mind and Language, 11, 160-190.

Dominowski, R. L. 1995. Content effects in Wason's selection task. In S. E. Newstead \& J. St. B. T. Evans (Eds.), Perspectives on thinking and reasoning: Essays in honour of Peter Wason (pp. 41-66). Hove: Lawrence Erlbaum,

Fiddick, L., Cosmides, L., \& Tooby, J. 2000. No interpretation without representation: The role of domainspecific representations in the Wason selection task. Cognition, 77, 1-79.

Hiraishi, K., \& Hasegawa, T. 2001. Sharing-rule and detection of free-riders in cooperative groups: Evolutionarily important deontic reasoning in the Wason Selection task. Thinking and Reasoning, 7, 255-294.

de Jong, P. J., Mayer, B., \& van den Hout, M. 1997. Conditional reasoning and phobic fear: Evidence for a fear-confirming reasoning pattern. Behaviour Research and Therapy, 35, 507-516.

Kikuchi, M., Watanabe, Y., \& Yamagishi, T. 1997. Judgment accuracy of other's trustworthiness and general trust: An experimental study. Japanese Journal of Experimental Social Psychology, 37, 23-36.

Kitamura, T. 1993. Hospital anxiety and depression scale. Archives of psychiatric diagnostics and clinical evaluation, 4, 371-373.

Kosugi, M., \& Yamagishi, T. 1996. Trust and gullibility. Proceedings of the 37th Annual Meetings of the Japanese Social Psychological Association, 288-289.

Manktelow, K. I., \& Over, D. E. 1991. Social roles and utilities in reasoning with deontic conditionals. Cognition, 39, 85-105.

Nagata, T., Kiriike, N., Matsunaga, H., Iketani, T., Yoshida, M., \& Yamagami, S. 1994. A trial of Eating Disorder Inventory (EDI) with eating disorder patients. Japanese Journal of Clinical Psychiatry, 23, 897-903.

Newstead, S. E., \& Evans, J. St. B. T. 1995. Perspectives on thinking and reasoning: Essays in honour of Peter Wason. Hove: Lawrence Erlbaum.

Newstead, S. E., Handley, S. J., Harley, C., Wright, H., \& Farrelly, D. 2004. Individual differences in deductive reasoning. The Quarterly Journal of Experimental Psychology, 57A, 33-60.

Oaksford, M., Morris, F., Grainger, B., \& Williams, J. M. G. 1996. Mood, Reasoning, and Executive Processes. Journal of Experimental Psychology: Learning, Memory, and Cognition, 22, 476-492.

Smeets, G., de Jong, P. J., \& Mayer, B. 2000. If you suffer from a headache, then you have a brain tumour: Domain-specific reasoning 'bias' and hypochondriasis. Behaviour Research and Therapy, 38, 763-776.

Sperber, D., Cara, F., \& Girotto, V. 1995. Relevance theory explains the selection task. Cognition, 57, 31-95.

Stanovich, K. E., \& West, R. F. 1998. Cognitive ability and variation in selection task performance. 
Thinking \& Reasoning, 4, 193-230.

Stanovich, K. E., \& West, R. F. 2000. Individual differences in reasoning: Implications for the rationality debate? Behavioral and Brain Sciences, 23, 645-726.

Stanovich, K. E., \& West, R. F. 2003. Evolutionary versus instrumental goals: How evolutionary psychology misconceives human rationality. In D. E. Over (Ed.), Evolution and the psychology of thinking: The debate (pp. 171-230). Hove, UK: Psychology Press.

Tonan, K., Sonoda, A., \& Ono, Y. 1995. Production of the Japanese edition of the Subjective Well-Being Inventory: Its reliability and validity. Japanese Journal of Health Psychology, 8, 12-19.

Tooby, J., \& Cosmides, L. 1990. On the universality of human nature and the uniqueness of the individual: The role of genetics and adaptation. Journal of Personality, 58, 17-68

Wason, P. C. 1968. Reasoning about a rule. Quarterly Journal of Experimental Psychology, 20, 273-281.

Yamagishi, T. 1998. The structure of trust. Tokyo: University of Tokyo Press. (In Japanese; English version is available at the author's website: http://lynx.let.hokudai.ac.jp/members/yamagishi/english.htm)

(Manuscript received March 30, 2004; Revision accepted September 17, 2004) 